\title{
TWO NEW BEMBECIDS (HYMENOPTERA) FROM THE CHANNEL ISLANDS, CALIFORNIA.
}

\author{
By Chas. L. Fov, San Fransico, Cal.
}

Bembix hamata sp. nov.

Male: Black; labrum, mandibles except apex, broad base and narrow lateral margins; clypeus; lower part of frons between antennal bases (angled dorsally); scape below; broad anterior orbits much shortened above; very narrow posterior orbits, abbreviated above and much shortened below at lower fourth of eye from mandibles; fascia on the first tergite reduced to small subovate lateral spots; narrow undulate fascia on tergites 2-6, usually narrowly interrupted medially, except that on 6 which is continuous and strongly notched on posterior border; small spot on each side apical area of ultimate tergite, sometimes wanting, lateral spots of sternites $2-5$, sometimes very small ones on 6 , an apical wedge shaped stripe on femora above, longer on anterior pair, tibiæ except black stripe on posterior surface and tarsi, all dull greenish yellow, the tarsi having a rusty tinge. Segments 7-9 of flagellum sub-spinose on posterior border; segments 9-11 bearing large open flat depressions, the ultimate segment a trifle longer than the preceding, only slightly curved, almost as broad at the roundedly truncate apex as at the base; intermediate femora below irregularly serrate-dentate; second sternite bearing a median hooked process distinctly higher than its basal length, much as in foxi, the sixth bearing a prominent oblique process narrowed and more produced posteriorly than in nubilipennis; this sternite also bearing a similar pair of rounded lateral processes or ridges; seventh sternite with a prominent median carina. Inner margins of the eyes nearly parallel. Flagellum tinged with fulvous below. Wings hyaline, veins dark brown. Head, thorax, median segment, base of abdomen, coxæ, trochanters and femora clothed with dense long pale pubescence, becoming longer and white beneath, the rest of the abdomen shorter-pubescent. 
Genital stipites shaped much as in comata as shown by Parker (fig. 163) but the inner margin more arcuated before the apical notch, the hairs longer and confined to the inner half of the surface and the basal suture oblique for its whole length, as in Parkers' figure 169 . Length $18-20 \mathrm{~mm}$.

Both in the Handlirsch and Parker keys this species runs to nubilipennis from which it differs in the size and shape of the body (being very robust) and in the absence of maculation on the thorax, pattern of maculation on the tergites and sternites, color and maculation of the legs, spinose character of the segments of the flagellum, serrate dentations of the intermediate femora, the longer and more dense pale pubescence and the form of the male stipites. In general appearance this species somewhat resembles amona, principally on account of the robustness of the body and the pattern of maculation on the tergites, but from which it can readily be distinguished by the character of the processes on the second and sixth sternites, absence of maculation on the thorax, the much shorter apical spurs on the intermediate tibiæ and the form of the stipites. Like the related species this shows some variation in the yellow marking; two specimens have small spots on the tegulæ and one a larger spot at the inferior angle of the prothorax.

Described from twelve males taken by Mr. E. P. Van Duzee on San Miguel Island, Santa Barbara County, California, May $20,1919$.

Holotype, male, No. 928, Mus. Calif. Acad. Sci.; paratypes in the collection of the Academy and in that of the author.

Type locality; San Miguel Island, Calif.

Bembix hamata subsp., lucida subsp. nov.

Male: Black; labrum, mandibles except apex and very narroe base; clypeus, lower part of frons between antennal bases (angled dorsally); anterior orbits, much shortened above, narrow posterior orbits slightly shortened above and below almost reaching base of mandibles; posterior edge of tubercles continued 
in a narrow stripe down the sides of the prothorax; tegulæ except apex; fascia on first tergite, very widely interrupted medially, shortened to large elongated lateral spots; fasciæ on tergites 2-5, continous and undulate on anterior border, deeply notched on posterior, that on sixth covering entire tergite except narrow posterior edge; large quadrate spot on apex of ultimate tergite, emarginate anteriorly; lateral spots on sternites 2-6; femora distally above and below; anterior tibiæ except broad stripe below and narrow one above, intermediate and posterior except short stripe below, and tarsi, all greenish yellow. The markings of head and femora below are more of a greenish white (in the species yellow). The segments of the flagellum have the same characters and color as in the species; the intermediate femora are more strictly dentate than in the species. The second sternite bears a large median hooked process (not so high as in the species), and the sixth a shorter and more acute median process and less prominent lateral ridges; seventh with a prominent median carina. The characters of the eyes and pubescence are the same as in the species.

This subspecies can readily be distinguished from the typical form of the species by the maculations on the head, thorax and abdomen and the general clearer color.

Described from one male taken by Mr. E. P. Van Duzee on Santa Cruz Island, Santa Barbara County, California, May $18,1919$.

Holotype, male, No. 929 Mus. Calif. Acad. Sci.

Type locality; Santa Cruz Island, California. 

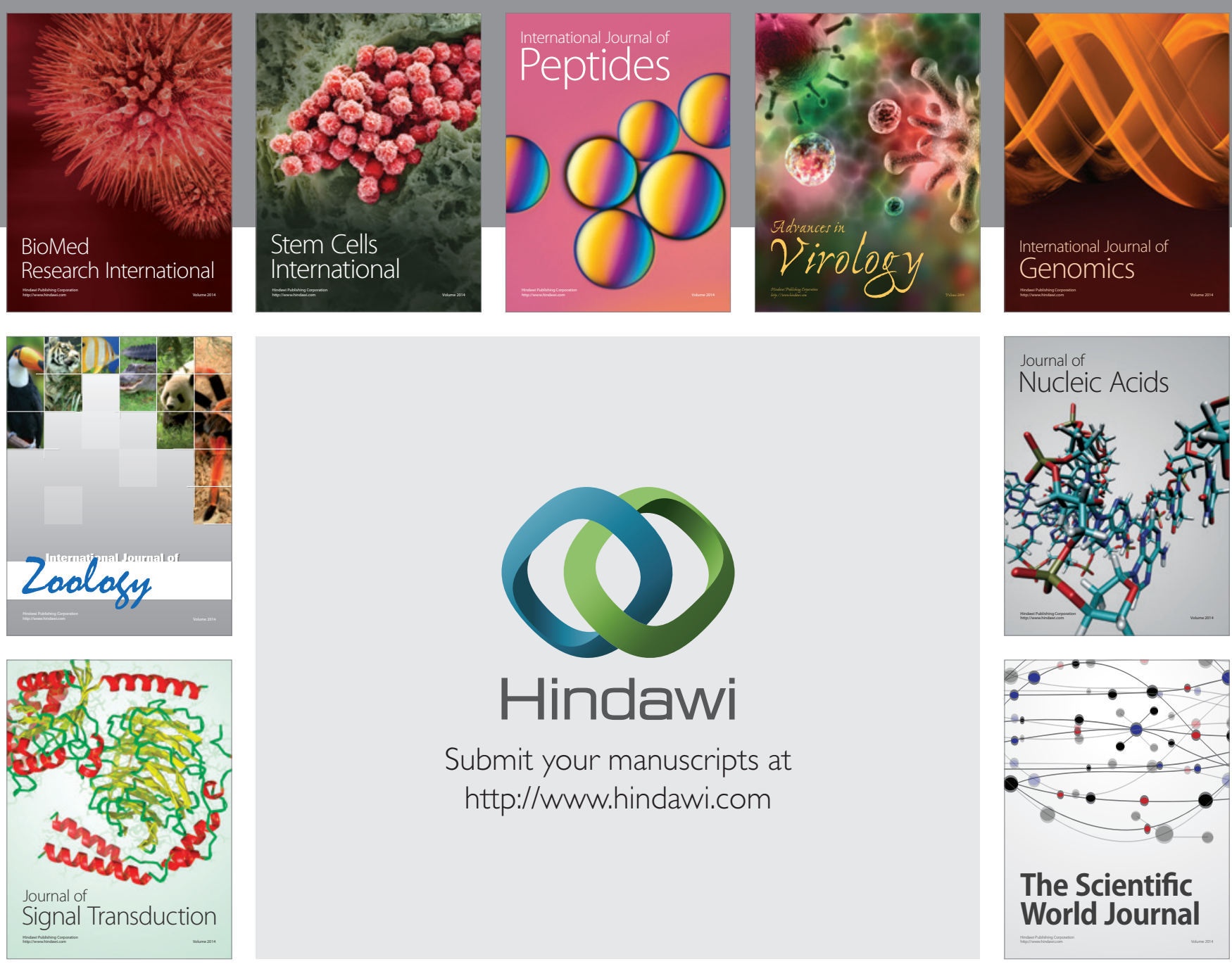

Submit your manuscripts at

http://www.hindawi.com
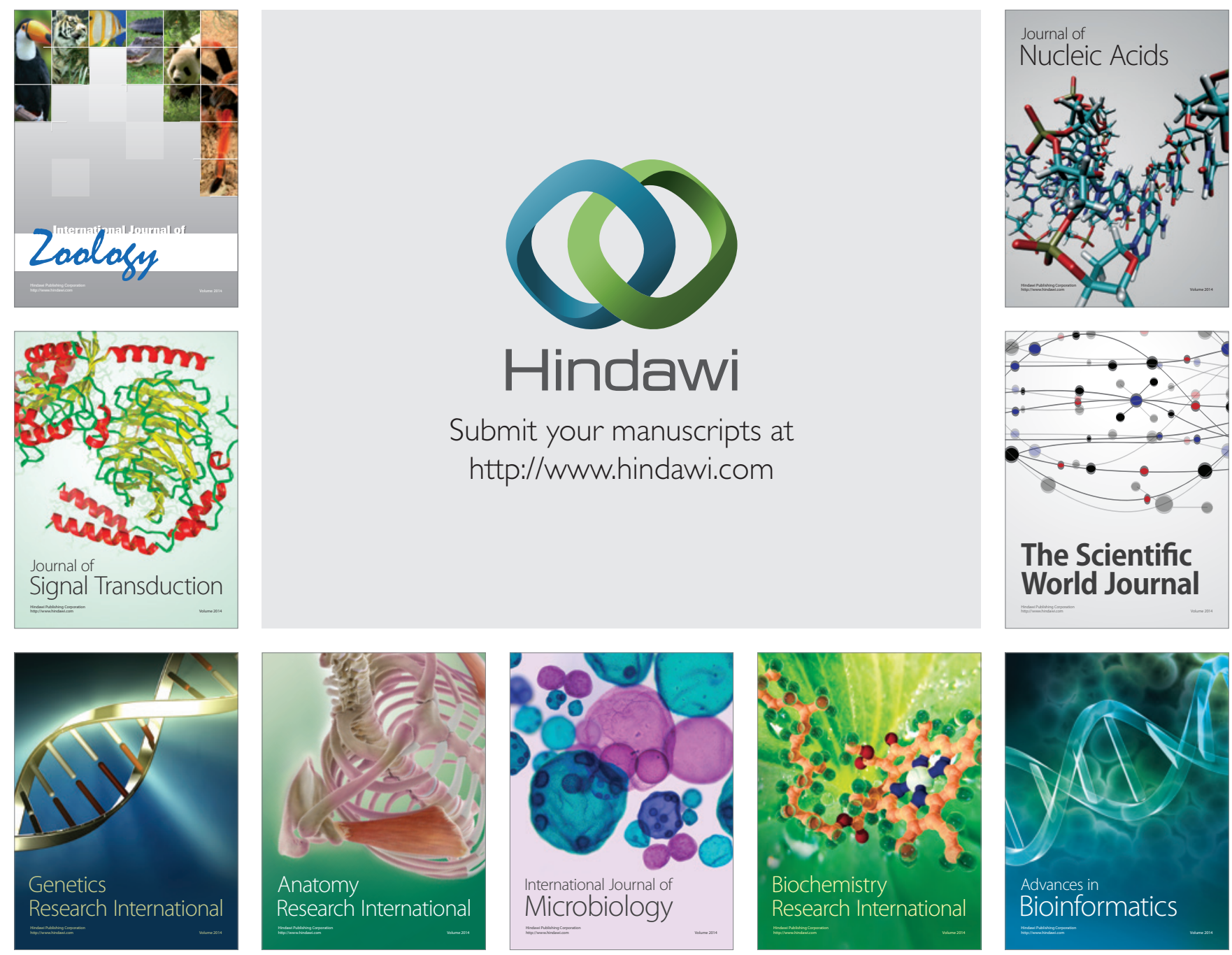

The Scientific World Journal
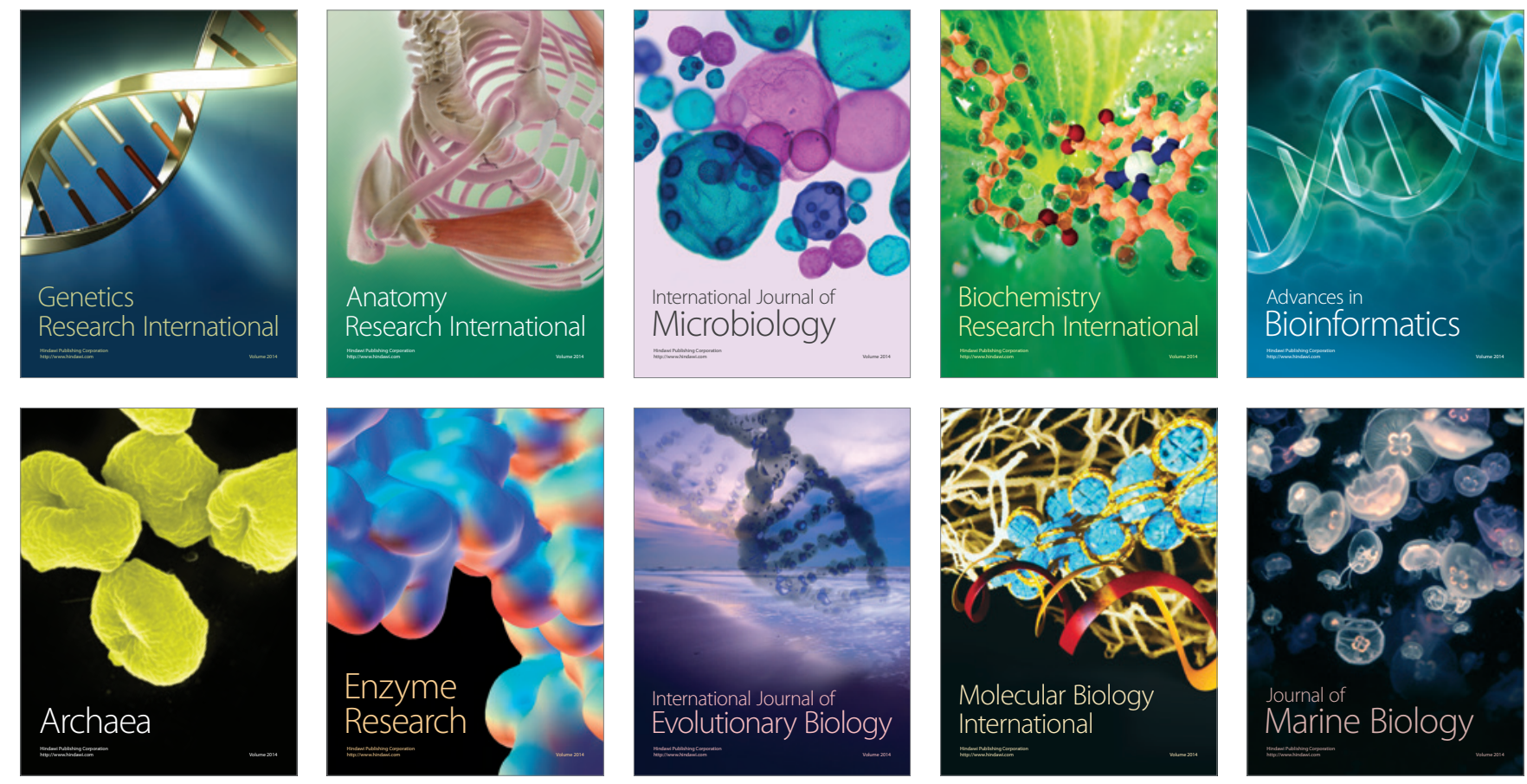